\title{
A BUSCA PELO EMPODERAMENTO FEMININO AO LONGO DA HISTÓRIA E COCO CHANEL COMO ÍCONE DAS MUDANÇAS NA VIDA DA MULHER DO SÉCULO XX
}

\author{
LA BÚSQUEDA DE EMPODERAMIENTO FEMENINO A LO LARGO DE LA \\ HISTORIA Y COCO CHANEL COMO UN ICONO DE LOS CAMBIOS EN LA VIDA DE \\ LA MUJER DEL SIGLO XX
}

\begin{abstract}
THE SEARCH FOR FEMALE EMPOWERMENT THROUGHOUT HISTORY AND COCO CHANEL AS AN ICON OF THE CHANGES IN WOMEN'S LIFE OF $20^{\text {TH }}$ CENTURY
\end{abstract}

Maria Angélica Seabra Rodrigues MARTINS ${ }^{1}$

RESUMO: O cinema e a literatura têm explorado a temática do "empoderamento" feminino de forma abrangente, evidenciando a opressão, na relação de igualdade homem-mulher, em um mundo eminentemente dominado pelos homens. Neste texto observaremos questões sobre a conquista de direitos da mulher, nos âmbitos profissional, familiar e pessoal, abrangendo a obtenção de poder e mudanças sociais ao longo da história. O direito ao voto e ao controle da natalidade, entre outros aspectos, além de algumas análises fílmicas do ícone feminino do século XX, Coco Chanel. Como suporte teórico-metodológico empregaremos noções de sociologia, de História e das Teorias do discurso.

PALAVRAS-CHAVE: Empoderamento. Direitos femininos. Sociologia. Teorias do discurso. Coco Chanel.

RESUMEN: El cine y la literatura han explorado el tema de "empoderar" a las mujeres de una manera integral, evidenciando la opresión, en la relación de la igualdad hombre-mujer, en un mundo eminentemente dominado por los hombres. En este texto observaremos preguntas sobre la conquista de los derechos de las mujeres, en las esferas profesional, familiar y personal, abarcando el logro de la energía y los cambios sociales a lo largo de la historia. El derecho al voto y al control de la natalidad, entre otros aspectos, además de algunos análisis fílmicos del icono femenino del siglo XX, Coco Chanel. Como apoyo teórico-metodológico, emplearemos nociones de Sociología, historia y teorías de discurso.

PALABRAS CLAVE: Empoderamiento. Derechos de las mujeres. Sociología. Teorías del habla. Coco Chanel.

ABSTRACT: The cinema and literature has been explored the theme of female empowerment comprehensively: highlighting women's oppression in the relationship of male-female equality in a world dominated by men. In this paper we will observe questions about the achievement of women's rights in the professional, family and personal matter, covering issues of attaining

${ }^{1}$ Universidade Estadual Paulista (UNESP), Bauru - SP - Brasil. Docente aposentada do Departamento de Ciências Humanas. FAAC/Unesp. ORCID: <https://orcid.org/0000-0003-4232-2932>. E-mail: masrm@uol.com.br

RPGE- Revista on line de Política e Gestão Educacional, Araraquara, v. 23, n. 2, p. 401-422, maio/ago., 2019. E-ISSN:1519-9029. 
power and social change throughout History. The right vote and birth control, among others, as well as film analysis of the feminine icon of the $20^{\text {th }}$ century, Coco Chanel. As theoretical methodological support will be employed notions of Sociology, History and Theories of Discourse

KEYWORDS: Empowerment. Women's right. Sociology. Discourse theories. Coco Chanel.

\section{Introdução}

A mulher, historicamente, tem sido objeto de opressão por parte do elemento masculino, considerada frágil, incapaz de tomar decisões e sem direitos a voto, à herança familiar, à decisão quanto ao número de filhos, entre outros aspectos, durante muitos séculos, sendo que algumas dessas questões como o direito ao voto e ao controle da natalidade, no século XX ela conseguiu obter vitória. Apesar dos povos em geral não a tratarem de forma igualitária à dos homens, se observarmos a história, algumas civilizações do passado, como a dos celtas consideravam-na um ser muitas vezes igual ou superior ao homem, sendo que uma rainha poderia subir ao trono e comandar exércitos com ou sem um marido, como fizeram Boudicca e Maeva. Também a rainha Cleópatra, do Egito, ousou desafiar Roma, em prol de seu povo.

No Egito, no século IV d.C., uma mulher - Hipátia ou Hypáthia - se destacou das demais, por sua capacidade intelectual e de ensinar na própria Academia de Alexandria, no século III d.C., sendo profundamente respeitada por seus alunos, devido a seus conhecimentos de matemática, filosofia, astronomia entre outros temas, escrevendo muitos livros e estudos relativos a suas pesquisas, que estavam na biblioteca de Alexandria, posteriormente queimada. Hipátia obteve por sua dedicação e conhecimento o que hoje denominaríamos "empoderamento", pois chegou a ser diretora do centro cultural mais importante da época.

O fim trágico de Hipátia pelo cristianismo retrógrado, fanático e machista fez com que a condição feminina, ao longo dos séculos seguintes, se restringisse ao casamento ou ao convento. Toda e qualquer instrução lhe foi negada, pois a igreja católica, então dominante no Império Romano, desde Constantino, considerava perigoso levar o conhecimento aos fiéis, pois poderiam utilizá-lo "de maneira errônea". No caso da mulher, havia a agravante de ela ser vista como um ser que teria conexões com o demônio; dessa forma, jamais poderia ser uma estudiosa. Algumas que procuravam se instruir terminavam em um convento (como no caso de Héloise, a amada do filósofo Abelardo; e de Santa Tereza de Ávila, doutora da igreja); ou, na pior das hipóteses, em uma fogueira, queimadas como bruxas. 
No século XII, entretanto, o rei Guilherme de Aquitânia ignorando essas leis retrógradas da Igreja, preparou sua filha Eleonora para sucedê-lo no trono, propiciando-lhe vasto conhecimento acerca das artes e das ciências conhecidas na época, além de levá-la em muitas viagens para que contatasse diretamente o povo que iria governar. O resultado foi uma mulher forte, que trouxe hábitos civilizados para as cortes de Aquitânia, França e Inglaterra, uma vez que foi casada com os reis desses países, inclusive interferindo na própria política dos reinos. Eleonora também preparou suas filhas para serem mulheres fortes e exigirem o respeito dos homens, introduzindo o cavalheirismo nas cortes, além de hábitos civilizados de higiene. Após sua morte, aos 80 anos, esses hábitos foram gradativamente sendo negligenciados e a mulher novamente perdeu seu poder, tornando-se submissa ao marido.

Essa condição somente começará a se transformar no Renascimento. A interferência da mulher passou a ser sentida de forma subjetiva, pois apesar de seu papel ser o de se enfeitar para o marido e para os salões da nobreza, muitas cortesãs desfrutavam de grande poder ao tornarem-se favoritas do rei, como Madame Pompadour e Madame Du Barry, com grande prestígio junto a Luís XV. Mme. Pompadour, em particular, dotada de grande inteligência, na condição de amante e secretária confidencial do rei, influenciava politicamente as decisões reais, além de governar Versailles. À Du Barry, coube o papel de consolar o rei após a morte da Pompadour e de, instada por Richelieu, conseguir a demissão do duque de Choiseul ministro dos Negócios Estrangeiros e que urdira o casamento do Delfin Luís XVI com Maria Antonieta da Áustria. Ambas as cortesãs, portanto, tornaram-se mulheres "empoderadas", ainda que submetidas ao elemento masculino.

No século XIX, mulheres da classe social privilegiada desfrutavam de certo poder e liberdade de agir, o que não ocorria com as de classe média e, principalmente, com as operárias. Em comum, eram mulheres submetidas a seus maridos, sem direito a herança e extremamente prejudicadas em caso de divórcio. Motivadas pelo desejo de modificar sua situação, o direito ao voto tornou-se uma luta, a partir do movimento das chamadas "sufragistas", que uniu as diferentes classes sociais.

Neste texto iremos abordar a questão do empoderamento, a partir da ótica de igualdade de direitos entre homens e mulheres, enfatizando os momentos que marcaram no final do século XIX e início do século XX. Dois filmes serão abordados, enfatizando um ícone que alcançou grande prestígio junto às mulheres, por sua ousadia ao mudar os padrões femininos: Coco Chanel - antes de Chanel (2009) e Chanel e Igor Stravinsky (2009), o primeiro representando vida de Chanel de criança abandonada em um orfanato, até sua ascensão ao poder como famosa modista; o segundo, mais contundente, mostra a mulher de atitudes agressivas, ousada, fria, 
capaz de dirigir uma grande empresa e de romper tabus, modificando comportamentos, o que teve grande repercussão no público feminino. As abordagens teóricas e metodológicas serão utilizadas com base na Sociologia, na História e nas Teorias do discurso.

\section{Afinal, o que é "empoderamento"?}

Termo de origem inglesa, segundo Kleba e Wendhausen (2009, p. 735), empowerment, estaria na literatura voltada para "melhorar a situação de grupos mais vulneráveis" (Idem) "na tradição anglo-saxônica do liberalismo civil e religioso, a palavra empower tem como tradução os verbos transitivos autorizar, habilitar ou permitir" segundo as autoras, retomando Stotz e Araújo, 2004. Em nosso texto a palavra empoderamento, será adotada no sentido de fortalecimento da condição feminina e de igualdade de direitos, conforme já utilizaram outros autores da língua portuguesa:

Há dois sentidos de empoderamento mais empregados no Brasil: um se refere ao processo de mobilizações e práticas que objetivam promover e impulsionar grupos e comunidades na melhoria de suas condições de vida, aumentando sua autonomia; e o outro se refere a ações destinadas a promover a integração dos excluídos, carentes e demandatários de bens elementares à sobrevivência, serviços públicos etc. $\mathrm{em}^{2}$ sistemas geralmente precários, que não contribuem para organizá-los, pois os atendem individualmente através de projetos e ações de cunho assistencial (GOHN, 2004 apud KLEBA; WENDHAUSEN, 2009, p. 735).

A partir do primeiro significado, acredita-se que pessoas podem conferir poder a si mesmas, reagindo à situação de tutela, de dependência, de impotência, assumindo a condição de sujeitos ativos, "que lutam para si, com e para os outros por mais autonomia e autodeterminação, tomando a direção da vida nas próprias mãos” (HERRIGER, 2006a, p. 16; KLEBA; WENDHAUSEN, 2009, p. 735), conforme será observado nos filmes sobre Coco Chanel.

No Brasil, o termo adaptado por Paulo Freire do termo inglês "empowerment", define um conceito fundamental para entender as aspirações dos movimentos da sociedade civil: "É impossível falar em feminismo e movimento negro sem falar de empoderamento" segundo Freitas $(2017$, p. 1). 
Em 2016, a ONU Mulheres ${ }^{3}$ lançou uma cartilha que define a questão do poder feminino, principalmente no ambiente de trabalho, classificando em sete itens essa questão:

1. Estabelecer liderança corporativa de alto nível para a igualdade de gênero

2. Tratar todos os homens e mulheres de forma justa no trabalho - respeitar e apoiar os direitos humanos e a não discriminação

3. Garantir a saúde, a segurança e o bem-estar de todos os trabalhadores e as trabalhadoras.

4. Promover a educação, a formação e o desenvolvimento profissional das mulheres.

5. Implementar o desenvolvimento empresarial e as práticas da cadeia de suprimentos e de marketing que empoderem as mulheres.

6. Promover a igualdade através de iniciativas e defesa comunitária.

7. Mediar e publicar os progressos para alcançar a igualdade de gênero.

E acrescenta que, empoderar as mulheres é necessário para que participem integralmente de todos os setores da economia e em todos os níveis de atividade econômica para:

- Construir economias fortes;

- Estabelecer sociedades mais estáveis e justas;

- Atingir os objetivos de desenvolvimento, sustentabilidade e direitos humanos internacionalmente reconhecidos;

- Melhorar a qualidade de vida para as mulheres, homens, famílias e comunidades;

- Impulsionar as operações e as metas dos negócios (Idem, 2016).

Dessa forma, observa-se que, segundo a cartilha da ONU, deve-se empoderar as mulheres, com o objetivo de incrementar a economia mundial, implementando a igualdade de gêneros, no sentido de tornar as mulheres mais empreendedoras no mundo dos negócios. Entretanto, essa visão causa certo desconforto entre as feministas, segundo Tramontina e Schmitz (2017), uma vez que "sua compreensão acerca de seu significado é totalmente oposta" (Idem, p. 101). Segundo os autores, retomando Sardenberg (2009, p. 2):

na vertente feminista, o empoderamento está relacionado a todo o processo de libertação das mulheres. Isso significa dizer que empoderamento é quando as mulheres conseguem se libertar do poder patriarcal e tem a possibilidade de se autodeterminar, no sentido de colocar um basta à opressão de gênero. (Idem, p. 2)

Em Coco Chanel observa-se que, aos quinze anos, decididas a começar uma nova vida fora do orfanato, ela e a irmã empregam-se como cantoras em um bar, onde conhecerão seus futuros amantes, que lhes permitirão afastar-se de seu passado opressor, galgando espaço na

${ }^{3}$ Disponível em: http://www.onumulheres.org.br/wp-content/uploads/2016/04/cartilha_WEPs_2016.pdf 
sociedade, embora permaneçam ligadas, para isso, ao poder masculino, pois à mulher não era franqueado o direito de ir e vir e de ascender socialmente, a não ser a partir de um marido ou de um amante. Observa-se, a partir desse exemplo, que a questão do empoderamento feminino, "quando abordado sob o viés da discriminação de gênero", evidencia que homens e mulheres deveriam ter garantidos os mesmos direitos, segundo Tramontina e Schmitz (2017, p. 98). Em Chanel e Igor Stravinsky, em um momento em que ele e sua família de exilados russos dependem totalmente do apoio financeiro e estratégico de Chanel, já famosa e rica, para que ele possa continuar sua obra, ele a confronta, dizendo-se superior a ela, pois era um artista, enquanto ela era apenas uma costureira, o que evidencia a discriminação tanto de gênero, quanto profissional.

Essa ótica será analisada neste texto, por meio da abordagem fílmica, observando-se como ocorreram as tentativas e, finalmente, os sucessos alcançados pelas mulheres, em seu reconhecimento social, ao longo da história, utilizando-se não apenas uma ênfase sociológica, mas as teorias do discurso, no sentido de se apresentar as mulheres enquanto sujeitos "que lutam para si, com e para os outros por mais autonomia e autodeterminação, tomando a direção da vida nas próprias mãos" (KLEBA; WENDHAUSEN, 2009, p. 735 apud HERRINGER, 2006a, p. 16).

\section{O século XX e a luta pela obtenção de direitos pela mulher}

Segundo Marcelino (2016, p. 1) ${ }^{4}$ as primeiras manifestações para a obtenção de direitos e igualdade política e jurídica pelas mulheres, como o direito à educação, à propriedade e posses de bens, ao divórcio etc., surgiu no final do século XIX. Até então, os bens de uma família eram herdados pelo filho mais velho do casal e, na falta desse, por um parente próximo, o que a inglesa Jane Austen evidencia em seu romance "Orgulho e Preconceito" (1813), abordando o mesmo tema em outros de seus livros. Ela mesma foi uma pioneira, ao ousar publicar livros na condição de mulher, embora seu nome, como autora, fosse mantido em sigilo por muito tempo.

\section{O direito ao controle da natalidade}

${ }^{4}$ Disponível em: https://juntos.org.br/2016/01/especial-juntas-as-sufragistas-e-a-primeira-onda-do-feminismo/ 
No cenário histórico do início do século XIX, a mulher deseja reivindicar seus direitos tanto no trabalho, quanto na própria casa, quando decide assumir o controle sobre a maternidade, ou seja, o número de filhos que desejasse ter (sem sacrifício de sua saúde), direito que cabia exclusivamente aos homens, por meio do coito interrompido, o que não impedia que continuassem a surgir famílias numerosíssimas, principalmente entre os mais pobres, além das mortes das mulheres no parto ou em abortos clandestinos. Para auxiliar na diminuição desses problemas, os ativistas Annie Besant e Charles Bradlaugh, em 1877, na Europa, procuraram conscientizar as mulheres sobre seus órgãos reprodutores e suas funções, utilizando panfletos, escritos pelo médico americano Charles Knowton, que também enfocavam rudimentares formas para o controle da natalidade; mas esses ativistas foram presos e condenados por distribuírem panfletos considerados "libelos obscenos".

Nos Estados Unidos ocorreu uma "campanha de reforma social de 1914 até cerca de 1945 que visava a aumentar a disponibilidade de contracepção", 5 por meio da educação e legalização. A enfermeira Margaret Sanger e outras companheiras, preocupadas com as mortes das mulheres nos partos e nos abortos induzidos, principalmente entre as de classe social mais pobre, decidiram ignorar as leis que proibiam a distribuição de panfletos relacionados ao assunto ("obsceno") e lançaram o The Woman Rebel, "um boletim contendo debates sobre contracepção" (Idem), abrindo, em seguida uma clínica de controle de natalidade, imediatamente fechada pela polícia e Sanger sendo presa, como medida preventiva, por trinta dias.

A vitória, entretanto, não tardou, pois com a eclosão da Primeira Grande Guerra, o aumento de doenças venéreas entre os militares norte-americanos obrigou o governo a enquadrar a relação sexual e a contracepção em uma campanha como questões de saúde pública. A partir dessas mudanças, Sanger, em 1923, abriu nova clínica para ensinar o controle da natalidade, sem que houvesse "controvérsias ou prisões".

A partir de 1930, quando vitórias judiciais a favor da contracepção passaram a favorecer as mulheres, a Associação Médica Americana decidiu adotar a contracepção como componente central dos currículos das faculdades de medicina, embora tanto a comunidade médica, quanto as próprias mulheres continuassem a confiar em contraceptivos inseguros e ineficazes.

Em 1942, formou-se a Federação de Paternidade Planejada da América, criando uma rede nacional de clínicas de controle de natalidade. Após a Segunda Guerra Mundial, o movimento para legalizar o controle de natalidade chegou a uma conclusão gradual, uma vez que o controle de

${ }^{5}$ Disponível em: https://pt.wikipedia.org/wiki/Movimento_pelo_controle_de_natalidade_nos_Estados_Unidos 
natalidade foi plenamente aceito pela profissão médica e as demais leis anticontracepção [sic] já não eram mais aplicadas (Ibidem).

\section{O direito feminino ao voto}

Muitas mudanças, no tocante aos direitos da mulher, marcaram essa passagem do século XIX para o XX, sendo que a luta pelo direito ao voto, com as chamadas "sufragistas" surge nesse contexto de mudanças:

Quando mudaram do campo para as cidades, para trabalhar nas fábricas, as mulheres passaram a se conscientizar mais de seus direitos. A escritora inglesa Mary Wollstonecraft (1759-1797) foi a grande pioneira da defesa do voto feminino, em livros e manifestos publicados a partir de $1792 .{ }^{6}$

Desde a Grécia Antiga, após o advento da democracia, havia o desejo das mulheres de serem reconhecidas como cidadãs. A luta pela igualdade de direitos foi impulsionada no século XIX, com a luta pelo direito de voto, ou seja, para serem reconhecidas como cidadãs. No contexto de um mundo considerado moderno, pós Revolução Francesa e Pós Revolução Industrial na Inglaterra, a mulher apresenta-se envolta em um mundo em constantes transformações, no qual se torna pertinente a reivindicação por seus direitos, muito embora essas ideias revolucionárias surgissem mais entre as da classe média e alta, melhor informadas, pois essas mulheres liam jornais, participavam de reuniões cívicas e possuíam conhecimentos para reivindicar seus direitos, o que faltava às operárias, mergulhadas em extenuantes jornadas de trabalho, muitas vezes seguidamente grávidas.

E do ponto de vista das mulheres, motivos não faltavam para a revolta: se as condições de trabalho nas fábricas eram extremamente difíceis para o homem trabalhador da época, elas eram ainda piores para as mulheres. Devido ao estabelecimento de uma divisão do trabalho no interior do processo produtivo, à constante vigilância feita pela supervisão do capitalista nas fábricas e ao entendimento de que eram intelectualmente inferiores aos homens, as mulheres, junto às crianças, tinham longos dias de trabalho duro, recebendo menores salários comparados aos dos homens, com postos mais precários, obrigadas a lidar com todo tipo de assédio moral e sexual, além de receber um tratamento conservador dos maridos em casa, desempenhando ainda as tarefas domésticas, como cuidado dos filhos. Ou seja, as mulheres trabalhadoras viviam uma vida miserável, não possuíam praticamente nenhum direito civil e político garantido perante o Estado (MARCELINO, 2006, p. 4).

Com o advento da Primeira Guerra Mundial, chamadas a ocupar os lugares antes destinados aos homens (então no front), nas fábricas, nas empresas e nas indústrias de

${ }^{6}$ Disponível em: https://mundoestranho.abril.com.br/historia/o-que-foi-o-movimento-sufragista/ 
armamentos, também houve uma necessidade física de se libertar dos apertados espartilhos e usar roupas mais curtas e mais confortáveis, para exercerem essas funções, o que trouxe mudanças também no vestuário. Motivadas pelas desumanas condições de trabalho a que eram submetidas (já em 1911), após um incêndio no qual morreram carbonizadas cerca de 130 operárias, em Nova Iorque, as trabalhadoras também se revoltaram e se uniram às mulheres de classe média que lutavam pelo direito ao voto. Se as mais esclarecidas e de classe alta "tinham propriedades e, assim, a possibilidade de desenvolver sua individualidade e viver como desejassem" (Idem, p. 6), as de classe média precisavam lutar contra a opressão dos maridos, além de necessitarem obter treinamento profissional igualitário e oportunidades iguais de trabalho:

Enfrentavam, portanto, as razões masculinas listadas contra o trabalho feminino qualificado: "inferioridade do cérebro feminino" e "tendência natural" a serem mães, colocando-as também diante da necessidade de exigir direitos políticos e derrubar as barreiras que foram criadas contra a sua atividade econômica. $\mathrm{O}$ mundo estava em ebulição e as mulheres clamavam por mudanças e pelo reconhecimento de seus direitos (Ibidem, p. 6).

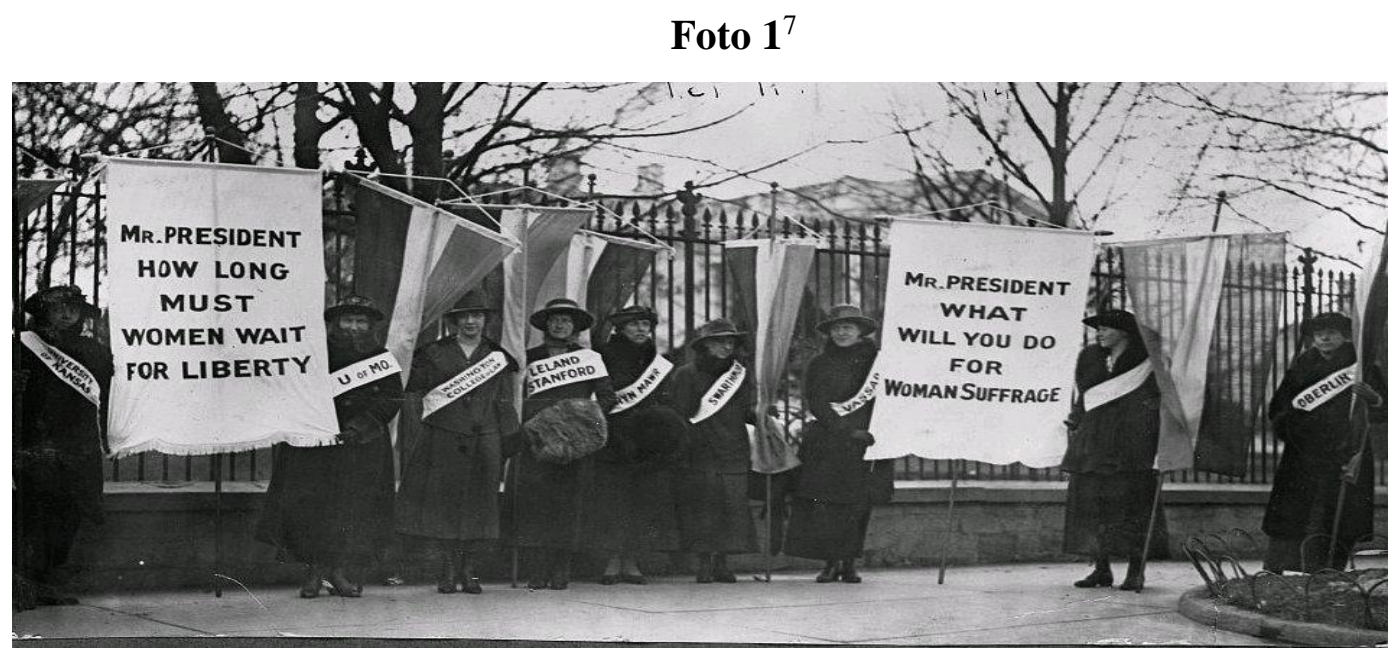

Todos esses aspectos são explorados e demonstram a difícil condição da mulher, que começa sua luta mais acirrada no princípio do século XX, como exemplifica o filme "As sufragistas" (2015), dirigido por Sarah Gavron. A luta das sufragistas inglesas teve sucesso, obtendo o direito ao voto, logo após o término da Primeira Guerra Mundial. Nos Estados Unidos, elas alcançaram esse direito em 1919, embora outros países já o tivessem concedido 
muito antes, como a Rússia, em 1917, a Finlândia, em 1906 e a Nova Zelândia, em 1893. No Brasil, esse direito foi definitivamente concedido por Getúlio Vargas, em 1934.

A luta pelo direito ao voto, após muitos piquetes, prisões e abandono por parte de muitos maridos, que eram contra essas mudanças reivindicadas pelas esposas sufragistas, marcará o início de muitas mudanças na condição feminina

Nesse contexto, em 1910, surge um ícone que iria simbolizar as transformações da mulher, tanto no mundo da moda, quanto nos costumes. Coco Chanel abre sua primeira loja de chapéus em Deauville, França, trazendo novos padrões também no vestuário feminino, como o uso de calças compridas pelas mulheres, além das roupas mais curtas e funcionais, concedendo um comportamento mais liberal aos movimentos. Mas o lançamento de seu perfume, em um momento em que esse produto não era um requisito explorado pela moda, desde a era vitoriana, em que o recato era a tônica, marcará um aspecto da sensualidade feminina, aliado ao bom gosto e fama da Maison Chanel, que definirá um novo aspecto no comportamento feminino, inclusive entre as conservadoras mulheres da classe alta: o da sedução. Dessa forma, Chanel surge como uma demolidora de tabus e uma transformadora de valores, que terá uma atuação direta sobre essas mulheres que reivindicavam mudanças.

\section{Coco Chanel e a liberdade da mulher}

Em 2009, são lançados dois filmes sobre Chanel: "Coco - antes de Chanel” (2009), com direção de Anne Fontaine; e "Coco Chanel \& Igor Stravinsky" (2009), do diretor Jan Kounern. O primeiro, com Audrey Tautou no papel-título, apresenta a infância da menina Gabrielle Chanel e o abandono pelo pai, aos seis anos, juntamente com a irmã, Adrienne (8 anos), após a morte da mãe, em um orfanato, onde permanecerão até os 15 anos de Gabrielle, quando começarão a cantar em um simples cabaré, encontrando seus primeiros amantes. Baseado na obra de Edmond Charles-Roux (1974), a história apresenta o destino de uma mulher que exerceu o seu poder à frente de uma grande empresa, foi o ponto focal de uma era, embora tenha sido considerada, ao longo de sua existência, uma marginal, "irregular". Nascida em uma classe social inferior, abandonada em um orfanato, lutou com as armas de que dispunha, no caso, os amantes para poder galgar seu lugar na sociedade da época. Sua vida marca a transição da jovem "conservadora e contida" em "moderna", bem de acordo com o espírito da época, obtendo seu "empoderamento".

Essa irregularidade surge na Paris dos anos 20, no meio artístico, entre pessoas como Cocteau, Reverdy, Diaghilev, Colette, que rompiam totalmente com os tabus. Étienne Balsan 
(Benoît Poelvoorde) é o primeiro amante e protetor, apelidando-a de "Coco", e figurativizando em nível discursivo da semiótica greimasiana, seu primeiro mecenas, que lhe permite sair da pobreza. A figurativização do "mecenas" reveste o tema "ascensão social" de Chanel. Ele a mantém em uma casa de campo, inicialmente proibindo-a de se mesclar a seus amigos da sociedade. Dessa forma, seu início como estilista é "irregulier", foge aos padrões normais de um cidadão bem-nascido, o que ela não era, uma vez que viera de um orfanato. Em nível fundamental ocorre a oposição regular x irregular no meio social.

Em determinado momento Coco/Audrey, ainda sob o ponto de vista da semiótica greimasiana é classificada como um sujeito de estado disjunta de seu objeto valor/ascensão social; mas ao se rebelar, passa a sujeito de fazer, motivada pelo destinador "vontade de ser diferente", utilizando da provocação, que se competencializa, segundo um saber-fazer, criando trajes inusitados, a partir das roupas do amante que ela ajustara a seu estilo como coletes e calças compridas para montar, o que causa estranheza entre os habituées da casa. Mas cujo desafio é sancionado positivamente pelo destinador, pois consegue impor sua forma de se vestir. Se, a princípio, era submissa, agora se firma enquanto mulher desafiadora, que não se deixa intimidar pelo escárnio dos amigos de Balsan. O que veste e os chapéus que usa, confeccionados por ela mesma, contrastam vivamente com os adereços exagerados das amigas de Balsan, que passam a lhe solicitar a confecção de adereços mais estilosos. Inicia-se sua obtenção de poder.

A libertação de Coco somente ocorrerá, entretanto, a partir de seu envolvimento com o rico inglês Arthur "Boy" Capel (Alessandro Nivola), um frequentador da casa, por quem se apaixona. Boy irá lhe financiar a loja de chapéus em Paris e, depois, o atelier de costura, ao qual imprime novos padrões, modelando as roupas nos corpos das clientes, apresentando saias mais curtas, amplas e pregueadas e roupas em tecidos até então empregados nos forros, como o jérsei, em modelos que tornaram as mulheres mais sensuais. Após a morte de Boy em um acidente de carro, já estava se consolidando a construção da poderosa figura de Chanel, de chapeleira em estilista famosa. 


\section{Foto $2^{8}$}

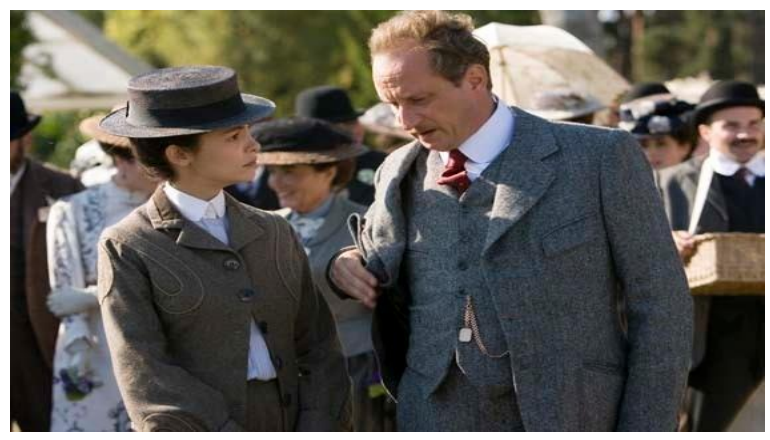

Foto 3

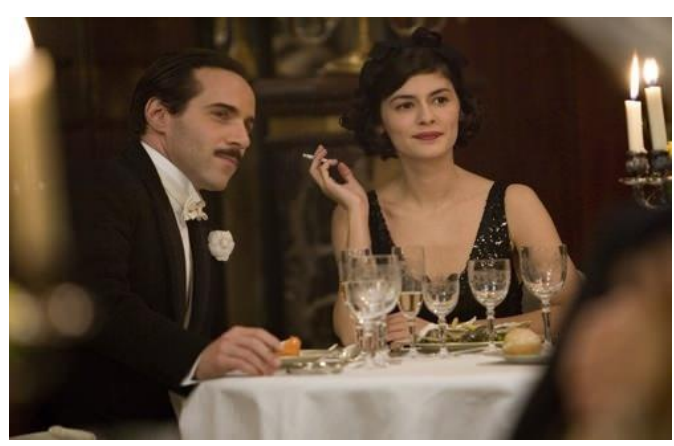

\section{Coco Chanel \& Igor Stravinsky}

O outro filme, objeto de análise deste texto, é dirigido por Jan Kounen, com roteiro baseado no romance de mesmo título, de Chris Greenhalg (2009), apresenta uma Coco (Ana Mouglalis) mais agressiva, nada submissa e senhora de seus atos, totalmente "empoderada", graças ao apoio de Boy Capel. Na primeira cena, de posse de uma enorme tesoura, com um cigarro aceso nos lábios, tenta nervosamente arrancar os colchetes do espartilho que está usando, exclamando para Boy Capel (Anatole Taubman), que a interpela sobre o que queria fazer: "Eu quero respirar!":

${ }^{8}$ Fotos 2 e 3 disponíveis em: https://www.google.com.br/search?q=coco+\%26+igor+stravinsky\&client=firefoxb\&source $=1 \mathrm{~nm} s \& t \mathrm{tbm}=\mathrm{isch} \& \mathrm{sa}=\mathrm{X} \& \mathrm{ved}=0$ ahUKEwjq3PnstujSAhXFIJAKHX0LCbwQ_AUIBygC\&biw=1280\& bih $=689 \#$ tbm=isch \&q=coco+antes+de+chanel $*^{*}$

RPGE- Revista on line de Política e Gestão Educacional, Araraquara, v. 23, n. 2, p. 401-422, maio/ago., 2019. E-ISSN:1519-9029. 


\section{Foto 4}

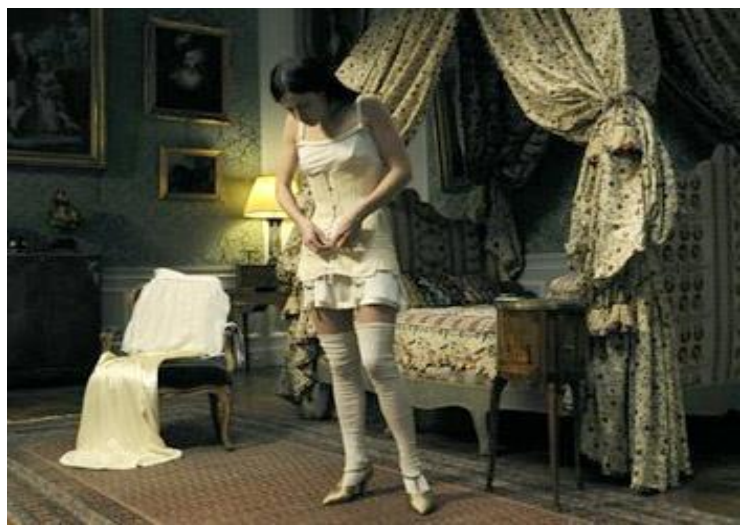

Foto $5^{9}$

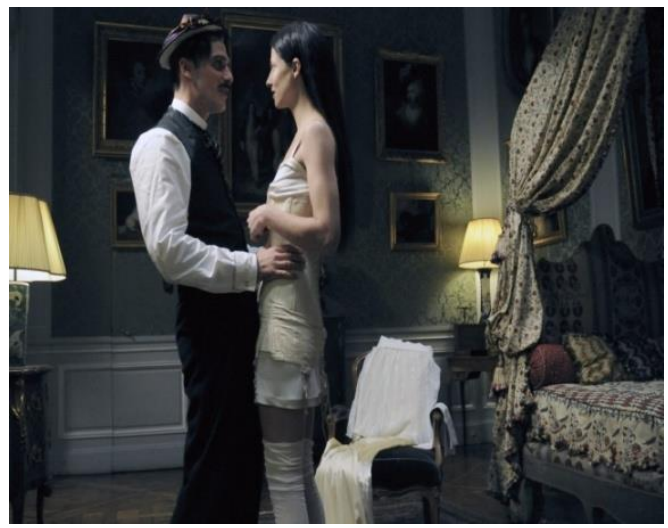

Essa cena figurativiza a mulher que rompe com valores e reveste o tema "desejo de liberdade" que imprimirá a seu estilo e será adotado pelas mulheres da época: sem amarras, sem opressões no vestir. Em nível de enunciação, o cigarro nos lábios e a destruição do espartilho constituem a marca da mulher que rompe com os valores do passado. Assim, surge, quebrando tabus, em uma festa, algum tempo depois da morte de Boy, com um vestido solto, de alcinhas, ombros nus, costas e colo à mostra, cujo comprimento deixa os tornozelos de fora, evidenciando, também, que não usa nem corpete, nem espartilho, muito embora a roupa seja preta, o que arranca comentários dos homens presentes, tais como "Até de luto ela fica elegante..."; e, com relação ao luto: "Foi o marido?", pergunta um outro. "Não, o amante", responde o primeiro, isotropias que reforçam a liberdade alcançada por essa ousada mulher. Dessa forma, contrastando com a mentalidade burguesa dos presentes, ousa aparecer de luto pelo amante, figurativizando a "irregular", porém assumindo o tema da "sensualidade explícita", não vulgar. A sensualidade é marca característica deste filme, contratando vivamente com a Chanel de Audrey Tautou, doce, inverossímil, muito pouco "Chanel”. O filme de Kounen

${ }^{9}$ Fotos 4 e 5 disponíveis em: https://www.google.com.br/search?q=coco+\%26+igor+stravinsky\&client=firefoxb\&source $=$ lnms \& tbm $=$ isch\&sa $=X \& v e d=0$ ahUKEwjq3PnstujSAhXFlJAKHX0LCbwQ_AUIBygC\&biw $=1280 \&$ bih $=689$

RPGE- Revista on line de Política e Gestão Educacional, Araraquara, v. 23, n. 2, p. 401-422, maio/ago., 2019. E-ISSN:1519-9029. 
apresenta Coco como uma mulher adiante de seu tempo, quando, ao assistir à primeira apresentação de "Sagração da primavera", de Igor Stravinsky (Mads Mikkelsen), em 1913, é a única a ficar fascinada pelo arrojado da obra, que foi vaiada pelo público em geral.

Após sete anos, Igor e sua família, agora refugiados da Revolução Bolchevique, em Paris, têm seu destino cruzado com o de Chanel. No percurso gerativo do sentido, no nível narrativo, o destinador executa fazeres da ordem do poder ou do dever-fazer, segundo valores de ordem eufórica ou disfórica, segundo Barros, 1988. Atraída pela obra de Stravinsky e já rica e famosa, como destinador, Coco executa o percurso da cortesia (eufórica), motivada pela tentação de transformar a situação financeira e familiar do músico, cuja peça a agradara sobremaneira, no passado. Competencializada pelo saber e pelo poder-fazer (é rica e dona de uma grande propriedade no campo "Bel Respiro", em Garches), realiza a performance de retirar do hotel miserável em que vivia a enorme família, amontoados em dois cômodos, levando-os a residirem em sua casa de campo, nos arredores de Paris, onde a esposa tísica do compositor poderia se recuperar, ele teria uma sala exclusiva para compor e os filhos, um grande parque para brincar. Dessa forma, é sancionada positivamente, enquanto destinador, em suas ações, pois obtém seu intento. Nesse momento da narrativa fílmica, Chanel figurativiza a perfeita anfitriã, revestindo o tema do acolhimento, pois a família, encantada com a casa e com o gesto de Coco, mostra-se profundamente agradecida. Dessa forma, nesse percurso o sujeito de fazer obtém a sanção positiva do destinador.

Observa-se que ela, enquanto sujeito, utiliza do mesmo estratagema de Étiene Balsan empregara com a jovem Coco, antes do início de sua carreira. Logo ao chegarem, os russos estranham a casa toda em tons de preto e branco, uma característica de Chanel, que também se verificará no decorrer do filme, e que surge como elemento enunciativo de seus dois lados, que se oporão: o de benfeitora e o de traidora. Katia (Elena Morozova), a esposa, em princípio executa timidamente um percurso de um sujeito de fazer, segundo a intimidação: coloca sua marca na cabeceira da cama do casal, estendendo uma tapeçaria russa em que predomina a cor vermelha (como seus cabelos), a fim de quebrar o clima instaurado pela dona da casa, embora enquanto destinadora de uma ação, não obterá a sanção positiva, uma vez que Coco não se deixará intimidar. No decorrer da narrativa, Kátia se tornará apenas um sujeito de estado que, incapacitada de executar uma performance (um fazer-fazer), uma vez que necessitam do auxílio financeiro e também da moradia de Coco, presencia a mesma conquistar seu marido e envolvêlo em uma teia de sedução cada vez maior, sem reagir, no papel de um sujeito de estado que fica disjunto de seu objeto valor/amor do marido. Kátia figurativiza a esposa submissa, pura, recatada, inclusive sendo representada com os cabelos vermelhos, a pele muito clara e as 
sobrancelhas raspadas (ou inexistentes), similar à rainha Elizabeth I da Inglaterra, a chamada Rainha Virgem. Neste momento da narrativa pode-se observar Coco utilizando a cortesia para com todos, inclusive presenteando a filha do casal com um belo vestido, e trazendo um médico para cuidar da saúde de Kátia, muito embora pratique um sexo selvagem com Igor, na sala de música, sem a preocupação de serem vistos. É o percurso da dissimulação.

Embora no nível do parecer Coco seja o modelo de cortesia para com todos, em segredo elabora cuidadosamente o percurso da sedução de Igor. Primeiramente aproxima-se do músico a sós e lhe pede que a ensine a tocar piano, revestindo-o de valores positivos (ele é o grande músico). Em um segundo momento, Coco, utilizando um vestido de seda branca, bordado e solto, primeiramente despede-se da foto de Boy Capel, virando para baixo um porta-retratos com a foto de ambos, evidenciando algo que ela não gostaria que seu grande amor visse, enquanto uma lágrima escorre por sua face. A seguir, resoluta, transforma-se em um sujeito de fazer, entra na sala de música onde Igor está compondo, aproxima-se dele e, com a competência adquirida por suas ações anteriores em prol da família (o que lhe confere um poder-fazer), com um único gesto no pescoço, executa sua performance, soltando o vestido, que cai a seus pés, revelando-se nua diante dele. Sua sanção é positiva, pois Igor, um homem conservador e que muito deve a Coco, não resiste e se entrega a ela em uma relação sexual selvagem, no tapete da sala, completamente nus (algo fora do comum para um pai de família da época). A partir desse primeiro encontro, outros se repetem, enquanto Coco indiretamente influencia Igor, de forma a que sua música se torne mais vigorosa e flua com muita passionalidade.

\section{Foto $6^{10}$}

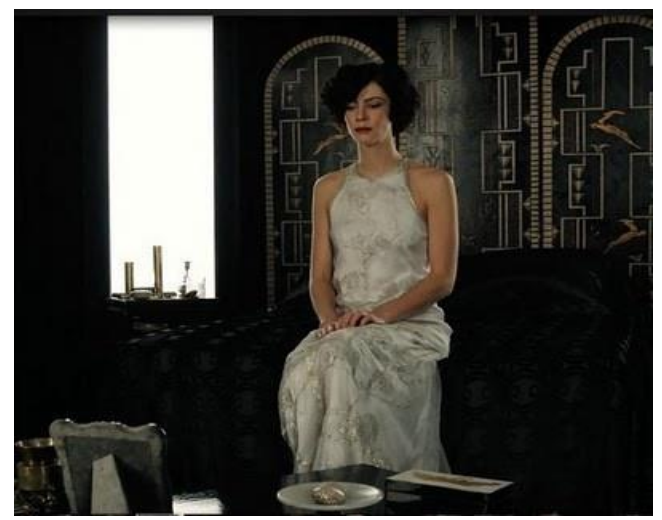

${ }^{10}$ Fotos 6 e 7 disponíveis em: https://www.google.com.br/search?q=coco+\%26+igor+stravinsky\&client=firefox-

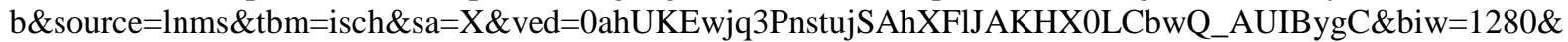
bih $=689$ 


\section{Foto 7}

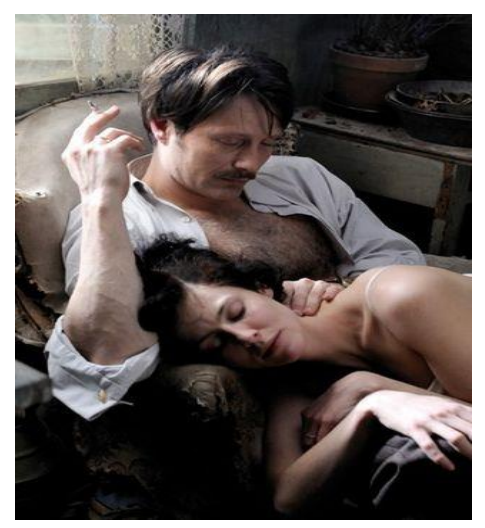

Essa paixão que envolve a ambos se reflete nas roupas que Coco passa a usar: um vestido em vários tons de vermelho, amarelo, marrom, branco e preto, que usa sob um casaco de jérsei (o tecido que adota) branco, marcas do abandono do luto. Novamente observa-se a passionalidade oculta pelo lado da gentileza, da cortesia, representado pelo casaco branco e pelos longos fios de pérolas, uma de suas marcas características. Em Grasse, assim vestida, experimenta vários odores trazidos pelo perfumista, mas rejeita todos, pois quer um que tenha “cheiro de mulher, não de flor". Ou seja, há uma insinuação de um perfume que remeta a sexo, não a inocência ("flor"), ao qual dá seu nome: "Chanel”, o número 5 acrescentado pelo perfumista, por ser a $5^{\mathrm{a}}$ amostra. Um exemplo dessa sensualidade marcante é levar Igor a seu quarto, no percurso da sedução, onde fazem sexo em lençóis de cetim (conhecidos pelo toque de sensualidade), um dos tecidos adotados por ela nas roupas, também. Na tentativa de provocar um afastamento entre Igor e a família, Coco diz que gostaria de passar uma noite inteira com ele em Paris, ao que ele retruca não poder fazer. Coco, enquanto destinador, continua com o percurso da provocação, investindo o destinatário Igor de valores negativos, visando obter a aceitação dele para seus propósitos. Dessa forma, indaga se ele não pode por causa da esposa:

-- Coco: Catherine? Só agora está pensando nela? Foi você que a deixou doente. Não vai fazer o mesmo comigo.

-- .... (Igor não responde).

-- Coco: Para você é como se eu não existisse. Não quero mais isso. Estou cansada.

-- ... (novamente o silêncio por parte de Igor).

-- Coco: Acha mesmo que um homem vale por duas mulheres? Não consegue escrever sua música sem que Catherine corrija depois. Eu sou tão poderosa quanto você, Igor. Só que faço mais sucesso.

-- Igor: Você não é uma artista, Coco. Você é uma vendedora de tecidos.

-- Coco: Saia! [cena do filme] 
Dessa forma, como o destinatário não aceitou a manipulação pela provocação, o destinador obtém a sanção negativa. Em nível discursivo, Coco figurativiza a mulher famosa, mas Igor, enquanto músico de formação clássica e homem conservador, não a vê como uma mulher moderna, independente e famosa. Logo, o tema desse nível discursivo é o da desigualdade de gênero homem/mulher. Em nível fundamental, a oposição "poder masculino" contrasta com a "Inferioridade feminina".

Agastada com ele, Coco inicia um novo movimento no sentido de provocar a esposa, embora ainda de forma sutil. Durante o jantar, enquanto Katia, a esposa recatada, ora com a família, Chanel apenas observa a cena, provocativamente fumando um cigarro, sentada à cabeceira da mesa. Em nível enunciativo, os valores familiares se opõem aos da mulher liberada.

\section{Foto $8^{11}$}

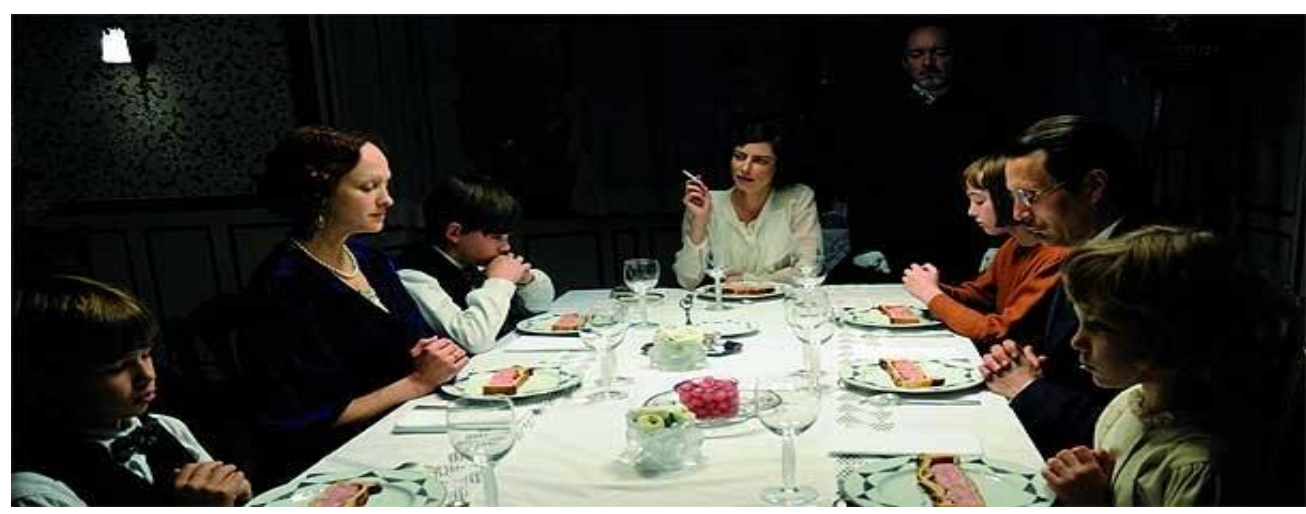

Em uma festa que oferece a seguir, em sua casa, apesar de usar um vestido branco com uma pala de plumas negras, os lábios estão com um batom vermelho vivo e os cabelos penteados com algumas ondas, bem junto à cabeça, assentados com gomalina, o que figurativiza a mulher fatal dos modelos da época, também evidenciado pelo cigarro sempre aceso entre os dedos, tematizando a mulher liberada. No intuito de provocar Igor, para que sinta ciúme, e também intimidar a família russa, mostra-se extremamente sedutora para com um novo talento musical que lhe é apresentado por Diaghilev, também conversando com seus amigos do meio social a que pertence, negligenciando a cortesia para com Igor e sua família. Enquanto sujeito, ela obtém a sanção positiva nesse percurso, pois o destinatário Igor levanta-se bruscamente e dirige-se ao

11 Foto 8 disponível em: https://www.google.com.br/search?q=coco+\%26+igor+stravinsky\&client=firefoxb\&source $=\operatorname{lnms} \&$ tbm $=$ isch \&sa $=X \& v e d=0$ ahUKEwjq3PnstujSAhXFIJAKHX0LCbwQ_AUIBygC\&biw $=1280 \&$ bih $=689$

RPGE- Revista on line de Política e Gestão Educacional, Araraquara, v. 23, n. 2, p. 401-422, maio/ago., 2019. E-ISSN:1519-9029. 
piano, tocando vigorosamente, na tentativa de mostrar seu valor. É o início do embate entre ambos que se intensificará, quando Igor deixa claro que não abandonará a família por ela.

\section{Foto $9^{12}$}

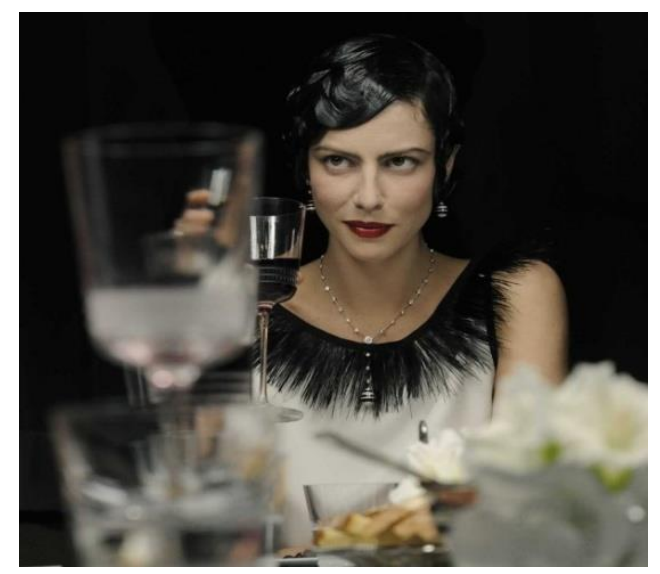

\section{Foto 10}

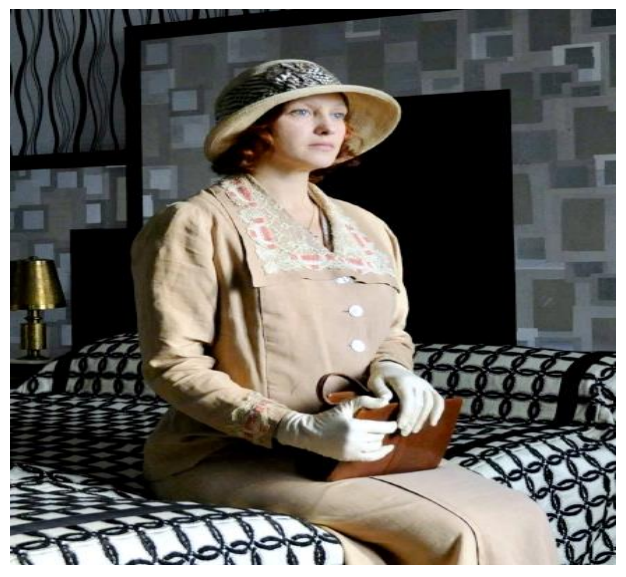

Katia, observando a situação, confronta Chanel, assumindo o papel de sujeito de fazer, segundo a intimidação, perguntando-lhe se não sente culpa pelo que está fazendo, ao que a antagonista responde que não. Dessa forma, o destinador Kátia obtém a sanção negativa. Neste momento da narrativa, Kátia figurativiza a esposa traída, e Chanel o da sedutora, revestindo o tema da "traição". Com os filhos como adjuvantes, também observando o que ocorre, só lhes resta afastar-se para Biarritz. Neste percurso (como no anterior), em nível enunciativo, a traidora e a traída se confrontam. Entretanto, após a partida, Chanel encontra sobre sua cama uma carta deixada por Kátia que, na condição de destinador, inicia o percurso da intimidação,

${ }^{12}$ Fotos 9 e 10 disponíveis em: https://www.google.com.br/search?q=coco+\%26+igor+stravinsky\&client=firefoxb\&source $=$ lnms \& tbm $=$ isch\&sa $=X \& v e d=0$ ahUKEwjq3PnstujSAhXFlJAKHX0LCbwQ_AUIBygC\&biw $=1280 \&$ bih $=689$

RPGE- Revista on line de Política e Gestão Educacional, Araraquara, v. 23, n. 2, p. 401-422, maio/ago., 2019. E-ISSN:1519-9029. 
executando um fazer que repercute fortemente na outra, ao abandonar Igor e a casa, deixando um bilhete sobre a cama de Coco:

Reconheço o favor que fez ao nos acolher. O que vem a seguir, para mim é um assunto mais difícil de abordar. Você sabe bem que a intimidade imoral que a liga a meu marido me causou um grande sofrimento. Mesmo admirando a mulher independente que você é, essa força que você tem, não consigo aceitar essa sua indecência. Eu imploro: escute seu coração. As crianças precisam do pai. A presença dele para nós é muito mais preciosa do que para você. [trecho do filme]

A sanção do destinador Kátia é positiva, pois na condição de destinatário, Coco sentese abalada e age segundo um dever-fazer/afastar-se de Igor. Considerando-se a própria história pregressa de Coco, abandonada pelo pai no orfanato e por quem sempre esperara inutilmente, o destinador/Kátia consegue executar uma performance capaz de manipular o destinatário Coco, que, a partir desse momento, passa a rejeitar Igor. Dessa forma, enquanto destinador, Kátia obtém a sanção positiva.

Coco passa a ignorá-lo e instala-se uma relação hipócrita entre ambos, pois mesmo auxiliando-o indiretamente nos momentos críticos para a produção da peça, Coco evidencia desprezá-lo, em várias atitudes, como a em que surge a cavalo, passa por ele a pé, entre as árvores, olha-o de cima a baixo e continua seu caminho. Nesse momento da narrativa ocorre o percurso do afastamento, por meio da intimidação. O empoderamento da mulher mais uma vez fica evidente nessa cena. Uma figurativização desse afastamento é a de Coco voltar a usar preto. Igor reage embebedando-se cada vez mais, mas agindo por meio da intimidação, o destinador Coco o obriga a terminar a peça, obtendo sanção positiva, quando ele consegue esse intento.

Em uma nova tentativa de evitar a rejeição, Igor, na condição de destinador de um novo percurso, na tentativa de atraí-la, utiliza da intimidação, ao dizer a ela que Diaghilev irá levar o balé para a Espanha e que ele e ela também irão. Mas Chanel não aceita a manipulação, ao retrucar que não é sua amante. Igor novamente tenta agir, agora segundo a tentação (que traz em seu bojo uma promessa, a de ficarem juntos), dizendo-lhe que não irá decepcioná-la, mas novamente Coco não aceita ser manipulada, respondendo-lhe que ele já a decepcionou. Ainda que não retomem o romance, ela colabora para que o projeto se concretize, ao desenhar os trajes da nova versão de sagração da Primavera, contribuir financeiramente (sem que ele saiba) e, ainda, acordá-lo das "homéricas bebedeiras", para que ele termine a peça.

No final, a sanção do destinador/Kátia, é positiva, pois Igor, desprezado, acaba por ir embora da casa, ainda que não haja indícios de que volte para a família, no filme, embora na 
vida real fique com a esposa até que ela morra, em 1939. O filme termina, mostrando Coco e Igor velhos e sozinhos, cada um em sua própria morada.

\section{Considerações finais}

Como se pôde observar ao longo deste texto, a condição feminina, ao longo da história, salvo situações pontuais como a de Eleonor da Aquitânia e de Boudicca e Maeva, foi de total submissão ao elemento masculino.

Somente após a Renascença mulher inicia tímida e subjetivamente, a retomada de seu poder junto ao homem, embora lhe coubesse o papel de embelezar os salões, sua atuação estava a cargo de dissimulações e manipulações sobre o mandatário masculino. Assim, se a ela era atribuída a relação com o belo, ao masculino cabia o poder de decisão, outorgado pela força física e pela virilidade.

Tal situação irá se modificar apenas no século XX, não apenas devido às duas Grandes Guerras, mas também às conquistas obtidas pelas sufragistas e pelas responsáveis pelas clínicas de controle da natalidade além das causas judiciárias em seu favor, e o direito ao trabalho com leis trabalhistas mais eficazes a seu favor.

Devemos, ainda, reconhecer a atuação de ícones revolucionárias como Coco Chanel que, não temendo a opinião pública, ousaram impor novos valores, apresentando a mulher como um ser mais independente, livre das opressões, pelo rigor dos tabus das classes sociais e capazes de expor sua real natureza, de forma muitas vezes hipócrita, mas com um fim em si mesma. Apesar dessas conquistas, a cartilha da ONU lançada em 2016, evidencia que no aspecto profissional, a mulher ainda sofre discriminações, com salários menores que os dos homens, embora ocupem cargos que outrora seriam impensáveis para o sexo feminino, como diretora de grandes empresas. Coco Chanel tornou possível evidenciar que às mulheres tudo era possível, desde que ousassem deixar a condição de submissão a que se relegaram durante toda a história.

\section{REFERÊNCIAS}

BARROS, D. L. P. Teorias do discurso. São Paulo: Atual, 1988

FIORIN, J. L. Linguagem e ideologia. São Paulo: Ática, 1988

FREITAS, A. A origem do conceito de empoderamento, a palavra da vez. NEXO JORNAL LTDA. Disponível em: https://www.nexojornal.com.br/expresso/2016/10/06/A-origem-doconceito-de-empoderamento-a-palavra-da-vez. Acesso em: 15 mar. 2018. 
GREENHALG, C. Coco Chanel \& Igor Stravinsky. London: Headline Publishing Group, 2002.

KLEBA, M. E; WENDHAUSEN, A. Empoderamento: processo de fortalecimento dos sujeitos nos espaços de participação social e democratização política. Saúde Soc. São Paulo, v. 18, n. 4, p. 733-743, 2009. Disponível em:

https://www.revistas.usp.br/sausoc/article/download/29498/31358. Acesso em: 15 mar. 2018.

MARCELINO, G. H. As Sufragistas: reflexões sobre o passado e o presente de luta das mulheres. Disponível em: https://juntos.org.br/2016/01/especial-juntas-as-sufragistas-e-aprimeira-onda-do-feminismo. Acesso em: 15 mar. 2018.

MARKALE, J. Alienor d'Aquitaine. Paris: Payot, 1983

ONU Mulheres Cartilha de empoderamento das mulheres. Disponível em:

www.onumulheres.org.br/wp-content/uploads/2016/04/cartilha_WEPs_2016.pdf. Acesso em: 15 mar. 2018.

ORLANDI, E. P. Análise de discurso, 6. ed. Campinas: Pontes, 2005

PILA, M. C. B. A. Manual de civilidade, modelos de civilização. Em: História em Revista (UFPel), Pelotas, v.9, p.105-134, 2003. Disponível em:

http://www.ufpel.edu.br/ich/ndh/downloads/historia_em_revista_09_maria_pilla.pdf. Acesso em: 15 mar. 2018.

REVEL, J. Os usos da civilidade. In: CHARTIER, Roger (Org.). História da vida privada: da renascença ao século das luzes. São Paulo: Companhia das Letras, 1991.

ROUX, E. C. L’Irreguliere - L'itinéraire de Coco Chanel. Paris: Éditions de Poche, 1974

SENNET, R. O declínio do homem público: as tiranias da intimidade. São Paulo:

Companhia das Letras, 1988.

TRAMONTINA, R; SCHMITZ, G. A. P. D. EMPODERAMENTO FEMININO: uma análise a partir da teoria do poder simbólico de Pierre Bourdieu. Revista de Gênero, Sexualidade e Direito. Brasília, v. 3, n. 1, p. 98 - 107 | Jan/Jun. 2017. Disponível em:

www.indexlaw.org/index.php/revistagsd/article/view/1826/pdf. Acesso em: 15 mar. 2018.

\section{Filmografia}

FONTAINE, A. (direção) Coco - antes de Chanel. Audrey Tautou. Warner Bross: França, 2009

GAVRON, S. (direção) As sufragistas. Carey Mullingan, Helena Boham Carter, Merryl

Streep. Focus: Reino Unido e Irlanda do Norte, 2015

KOUNEN, J. (direção) Coco Chanel \& Igor Stravinsky. Anna Mouglalis e Mads Mikkelse., Imovision: França, 2009 


\section{Como referenciar este artigo}

MARTINS, Maria Angélica Seabra Rodrigues. A busca pelo empoderamento feminino ao longo da história e Coco Chanel como ícone das mudanças na vida da mulher do século XX. Revista on line de Política e Gestão Educacional, Araraquara, v. 23, n. 2, p. 401-422, maio/ago., 2019. E-ISSN:1519-9029. DOI: 10.22633/rpge.v23i2.12528

Data de Submissão: 10/05/2018

Revisões Requeridas: 10/07/2018

Aceite em: 20/11/2018

Publicado em: 15/05/2019 